\title{
ARTICULAÇÃO ENTRE AS APRENDIZAGENS INDIVIDUAL, GRUPAL E ORGANIZACIONAL: UM ESTUDO NO AMBIENTE INDUSTRIAL
}

\section{THE ARTICULATION AMONG INDIVIDUAL, GROUP AND ORGANIZATIONAL LEARNING: A STUDY IN THE INDUSTRIAL ENVIRONMENT}

\section{DIÓGENES DE SOUZA BIDO}

Doutor em Administração de Empresas pela Faculdade de Economia, Administração e Contabilidade da Universidade de São Paulo (FEA-USP). Professor e pesquisador do Programa de Pós-Graduação em Administração de Empresas da Universidade Presbiteriana Mackenzie (UPM). Rua da Consolação, 896, térreo - São Paulo - SP - Brasil - CEP 01302-907 E-mail: diogenesbido@yahoo.com.br

\section{ARILDA SCHMIDT GODOY}

Doutora em Educação pela Faculdade de Educação da Universidade de São Paulo (USP). Professora e pesquisadora do Programa de Pós-Graduação em Administração de Empresas da Universidade Presbiteriana Mackenzie (UPM). Rua da Consolação, 896, térreo - São Paulo - SP - Brasil - CEP 01302-907 E-mail: arilda@mackenzie.br

BRUNO FELIX VON BORELL DE ARAUJO Doutorando em Administração de Empresas do Programa de Pós-Graduação em Administração de Empresas da Universidade Presbiteriana Mackenzie (UPM). Rua da Consolação, 896, térreo - São Paulo - SP - Brasil - CEP 01302-907 E-mail: felixbruno1@yahoo.com.br

\section{JONES CARLOS LOUBACK}

Doutorando em Administração de Empresas do Programa de Pós-Graduação em Administração de Empresas da Universidade Presbiteriana Mackenzie (UPM). Rua Pedro de Toledo, 175, Guarulhos - SP - Brasil - CEP 07140-901 


\section{RESUMO}

Este trabalho teve como objetivo principal verificar e analisar empiricamente a articulação entre os níveis individual, grupal e organizacional da aprendizagem. Os dados foram coletados em uma indústria de plásticos brasileira, contando com 46 respondentes de um total de 88 funcionários (52\%). A análise dos dados se deu pela modelagem em equações estruturais com estimação por mínimos quadrados parciais (Partial Least Squares - Path Modeling), na qual os construtos foram mensurados como variáveis latentes (VL) de segunda ordem. Os resultados foram comparados com aqueles obtidos em outros contextos, a saber: hospital (CHAN, 2003) e instituição bancária (BIDO et al., 2008). Como principal resultado, observou-se que os três construtos se correlacionam, mas a correlação entre a aprendizagem grupal (AG) e a organizacional (AO) foi a maior nos três estudos. Pode-se explicar esse resultado pela percepção dos respondentes de que o comportamento da equipe, realmente, seja o "portão de entrada" para a AO. Ao final do trabalho, são apontadas as suas limitações e sugeridas algumas direções para continuidade da pesquisa.

\section{PALAVRAS-CHAVE}

Aprendizagem organizacional; Aprendizagem grupal; Aprendizagem individual; Níveis de aprendizagem; Modelagem em equações estruturais.

\section{ABSTRACT}

This study aimed to verify and analyze empirically the relationship among the individual, group and organizational learning. Data were collected in a Brazilian plastics industry, with 46 respondents from a total of 88 employees $(52 \%)$. Data analysis occurred through structural equation modeling with estimation by partial least squares (Partial Least Squares - Path Modeling), in which the constructs were measured as latent variables of second order. The results were com- 
pared with those obtained in other contexts, namely: hospital (CHAN, 2003) and bank institution (BIDO et al., 2008). As main result, we observed that the three constructs are correlated, but the correlation between TL (team learning) and OL (organizational learning) was higher in the three studies. One explanation for this result may be due to the perception of respondents that the behavior of the team, really, is the "gateway" to the OL (organizational learning). At the end of the work, some limitations and directions for continuing the research are pointed.

\section{KEYWORDS}

Organizational learning; Team learning; Individual learning; Learning levels; Structural equation modeling.

\section{INTRODUÇÃO}

Ao revisar a literatura a respeito do tema aprendizagem organizacional (AO) do ponto de vista da ciência da administração, Pawlowsky (200I) estabelece uma estrutura conceitual com quatro dimensões integradas que, segundo esse autor, constituem os pilares para entender esse campo de estudo. As dimensões presentes no modelo de Pawlowsky (200I) abarcam algumas das questões que têm produzido acaloradas discussões a respeito do tema e envolvem os diferentes níveis, modos, tipos e processos de aprendizagem.

Ao analisar a literatura, Pawlowsky (200I) detectou que muitas das abordagens da AO estavam voltadas para a compreensão de um ou mais dos três modos de aprendizagem, a saber, cognitivo, cultural e da aprendizagem-ação. De acordo com o autor, esses três modos correspondem às diferentes formas existenciais que caracterizam a nossa condição como seres humanos: conhecer, sentir e agir. Mais do que excluir uma delas, o autor propõe que todos estes componentes conhecimentos, sentimentos e ações - devem ser considerados complementares quando se pensa na possibilidade de promover a aprendizagem no interior das organizações.

Os tipos de aprendizagem têm se constituído assunto polêmico desde os trabalhos seminais de Argyris e Schön (I996), embora outras tipologias tenham sido propostas por Shrivastava (I983) e Fiol e Lyles (I985). Apenas para ilustrar, apontam-se aqui os ciclos simples, duplo e triplo estabelecidos por Argyris e Schön (I996), que propõem que a aprendizagem pode assumir tanto formas meramente instrumentais quanto estar baseada em processos cognitivos ou nos mecanismos do "aprender a aprender". Entende-se aqui que, nas organizações, 
podem ser encontradas aprendizagens dos três tipos, o que dependerá das circunstâncias e da natureza do próprio conteúdo a ser aprendido.

Quanto às diferentes fases do processo de aprendizagem, Pawlowsky (200I) propõe quatro passos que não são necessariamente sequenciais e que envolvem: a identificação da informação e/ou criação do conhecimento, a difusão desse conhecimento, sua integração no sistema já existente e sua transformação em ação e aplicação na realidade organizacional. Embora Pawlowsky (200I) faça referência a outras propostas nesse sentido, elas não serão aqui apresentadas, podendo o leitor recorrer ao texto do autor para conhecê-las.

E, finalmente, a dimensão relativa aos níveis da aprendizagem que interessa mais de perto aos objetivos deste trabalho. Para Pawlowsky (200I), a aprendizagem organizacional deve ser entendida como distinta da aprendizagem individual, destacando-se o nível grupal, pois o grupo ou time funcionam como "portão de entrada" para a AO. Para esse autor, tal dimensão deveria envolver, pelo menos, quatro níveis analíticos de aprendizagem: individual, grupal ou interpessoal, organizacional ou intraorganizacional e interorganizacional ou network.

Embora Pawlowsky (200I) considere que todas essas dimensões estão interconectadas e devem ser levadas em consideração quando se examina determinado fenômeno de aprendizagem, o texto aqui apresentado foca especialmente a questão dos níveis, para a qual outros autores reconhecidos no campo da AO têm chamado atenção, conforme será apresentado a seguir.

Um levantamento efetuado por Antonello e Godoy $(2008,2009)$ nos principais periódicos e anais de congressos brasileiros, no período de 2001 a 2005 , envolvendo 94 artigos, informa que os estudos nacionais investigam, predominantemente, os níveis de análise organizacional (examinado em 58 artigos) e individual (examinado em 43 artigos), em detrimento de um maior investimento na compreensão dos níveis grupal e interorganizacional. Dos artigos examinados, apenas I4 estudos analisaram, simultaneamente, os níveis individual e organizacional. O nível grupal foi destaque em I7 artigos. Dentre estes, quatro estudaram os níveis grupal e individual, dois focaram os níveis grupal e organizacional e apenas um os níveis grupal e societal. Apenas seis estudos examinaram, simultaneamente, três níveis: individual, grupal e organizacional.

Esse tipo de resultado já tinha sido identificado em estudo nacional de autoria de Loiola e Bastos (2003), abrangendo 43 artigos publicados nos principais periódicos e anais de congressos, no período de I997 a 200I. No âmbito internacional, Bapuji e Crossan (2004) identificaram I23 trabalhos publicados no período de 1990 a 2002 , dos quais 55 (44\%) constituíam estudos empíricos. Ao analisarem essas pesquisas, constataram que 37 delas $(67 \%)$ usaram a organização como unidade de análise. Das restantes, I3 incluíam grupos ou múltiplos níveis de análise e cinco analisaram a aprendizagem individual. 
Com base nesses resultados, tanto os autores internacionais como os nacionais recomendam que as pesquisas deveriam desenvolver métodos e medidas de verificação empírica da $\mathrm{AO}$ abrangendo os diferentes níveis. Embora autores como Brown e Duguid (I99I), Lave e Wenger (I99I), Crossan, Lane e White (I999), Gherardi e Nicolini (200I) e Antonacopoulou (2006) venham discutindo a pertinência de focar o tema considerando que a $\mathrm{AO}$ ocorre em diferentes níveis e buscando uma visão mais integradora e holística, que procure compreender o fenômeno a partir de sua natureza coletiva, processual e situada, outros estudiosos do tema consideram que o estudo do relacionamento entre os diferentes níveis de manifestação da $\mathrm{AO}$ ainda precisa ser aprofundado.

Segundo Edmondson e Moingeon (I998), Pawlowsky (200I), Chan (2003), Lyles e Easterby-Smith (2003), López, Peón e Ordás (2005), entre outros, o desenvolvimento de métodos adequados à medida da $\mathrm{AO}$, que tragam indicadores do relacionamento entre seus vários níveis de análise, continua sendo relevante.

No contexto da discussão a respeito dos diferentes níveis envolvidos na AO, este trabalho tem como objetivo principal verificar e analisar empiricamente a articulação entre os níveis individual, grupal e organizacional da aprendizagem, e, como objetivo complementar, confirmar a validade e confiabilidade do instrumento escolhido para dar conta dessa tarefa.

No próximo item, apresentam-se os elementos teóricos que embasam o presente estudo; na seção 3, são descritos os procedimentos metodológicos utilizados na pesquisa empírica; nas seções 4 e 5, fazem-se a apresentação e análise dos resultados encontrados; e, finalmente, apresentam-se as considerações finais.

\section{REFERENCIAL TEÓRICO}

A discussão sobre como acontece a AO está presente nos trabalhos de Argyris e Schön (I996) e Kim (I998), que defendem que a aprendizagem organizacional (AO) ocorre a partir da aprendizagem individual (AI) de seus membros, ainda que o processo não seja uma simples ampliação da aprendizagem do indivíduo para a organização. Embora o indivíduo seja o agente da aprendizagem, as organizações não representam uma simples coleção de indivíduos. A questão básica para esses autores pode ser resumida na questão: "Como a aprendizagem individual é transformada em aprendizagem organizacional?”.

No modelo integrado de aprendizagem organizacional proposto por Kim (I998), os modelos mentais dos indivíduos são como codificações das mudanças vivenciadas ao longo do tempo, e a AI ocorrida afeta a AO, influenciando os modelos mentais compartilhados na organização. Para Kim (I998, p. 62), enquanto o indivíduo pode aprender sem a organização, esta “[...] pode aprender 
independentemente de qualquer indivíduo específico, mas não independentemente de todos os indivíduos".

Argyris e Schön (I996) alinham-se com esse pensamento enfatizando a importância das interações dos indivíduos no processo de AI e o compartilhamento da aprendizagem nos níveis coletivo, grupal e organizacional. Para esses autores, as organizações aprendem quando os indivíduos vivem uma situação problemática, quando questionam o comportamento da organização, percebem a diferença entre o esperado e o observado decorrente das ações, agem para modificar suas imagens da organização e reestruturam suas atividades.

Enquanto Argyris e Schön (I996) e Kim (1998) discutem especialmente o relacionamento entre os níveis individual e organizacional, Pawlowsky (200I) destacará o nível do grupo ou do time como especialmente relevante na passagem para a aprendizagem organizacional. Ainda que em seu modelo aborde diferentes níveis analíticos, Pawlowsky (200I, p. 75) dá destaque especial ao nível do grupo, pois

[...] grupos não são somente a ligação entre o indivíduo e a organização, mas também o crucial sistema social interveniente no qual [os indivíduos] compartilham, aprendem, e o comportamento organizacional se faz presente.

Outra autora que aborda a questão da aprendizagem nas organizações a partir do grupo ou times é Edmondson (1996, 1999). Assim como em Edmondson (2002), utilizam-se aqui os termos grupo e time como sinônimos, referindo-se a grupos de indivíduos que existem no interior de uma grande organização, compostos por membros claramente definidos, os quais compartilham responsabilidade pelos resultados, tais como produtos e serviços. Tal definição também encontra apoio no verbete "time" do Minidicionário Houaiss da língua portuguesa (HOUAISS; VILLAR, 2008, p. 726), que destaca como um dos significados para o termo: "[...] grupo de pessoas empenhadas numa mesma tarefa". O modelo de aprendizagem em times proposto pela autora considera três fatores interdependentes - os fatores estruturais, as crenças do grupo e os comportamentos de aprendizagem - que impactarão no desempenho do grupo. Nesse modelo, os fatores estruturais são condições inerentes ao grupo, afetando as crenças dos seus membros e colaborando indiretamente para o resultado final.

Revisando estudos anteriores sobre a aprendizagem nos times de trabalho, a autora destaca que estes tratam da importância das características estruturais e do contexto organizacional, deixando de lado os fatores interpessoais que afetam o comportamento e a aprendizagem. Em seus estudos, Edmondson (I996, I999, 2002) reconhece tanto a importância dos aspectos estruturais como dos 
interpessoais na aprendizagem e no desempenho dos grupos de trabalho. De acordo com essa autora, a aprendizagem, na perspectiva do grupo, ocorre por meio de um processo contínuo que envolve reflexão e ação, com base na compreensão e na experiência compartilhada.

Edmondson tem utilizado em seus trabalhos tanto metodologias qualitativas com dados obtidos por meio de entrevistas quanto metodologias quantitativas que recorrem à utilização de escalas como instrumento de coleta de dados. Dois de seus últimos estudos (EDMONDSON; MOINGEON; WOOLLEY, 2003; EDMONDSON, 2004) revelam contribuições importantes para a medida da aprendizagem no nível dos grupos ou times de trabalho.

Existe ainda um conjunto de autores que desenvolveram instrumentos para a medição da $\mathrm{AO}$ nos níveis individual, grupal e organizacional, sendo importante destacar alguns trabalhos internacionais e os estudos brasileiros que adaptaram e utilizaram tais instrumentos. Serão apresentadas as seguintes escalas: de Templeton, Lewis e Snyder (2002) utilizada por Souza e Trez (2006), de López, Peón e Ordás (2005) usada por Isidro Filho (2007), e de Chan (2003), objeto de estudo desenvolvido por Bido et al. (2008).

Na proposta de Templeton, Lewis e Snyder (2002), a AO é entendida como um processo efetivo de interpretação e resposta às informações internas e externas à organização, as quais podem ser quantitativas ou qualitativas, mas geralmente explícitas e de domínio público. A medição é realizada a partir de quatro temas que refletem o processo de aprendizagem (aprendizagem coletiva, aprendizagem individual, tipos de aprendizagem organizacional e o papel das estruturas de conhecimento) e de cinco temas operacionais organizados a partir dos quatro subconstrutos propostos na definição de Huber (I99I) para AO: aquisição de conhecimento, distribuição da informação, interpretação da informação e memória organizacional. A escala final consta de 28 itens indicadores de AO, organizados em oito fatores denominados: lembrança, comunicação, avaliação de performance, cultivo intelectual, adaptabilidade ambiental, aprendizagem social, gerenciamento do capital intelectual e esforço organizacional. No estudo brasileiro que utilizou uma adaptação dessa escala, Souza e Trez (2006, p. I2), mesmo com uma pequena amostragem (I2 empresas com menos de Ioo funcionários e I8 empresas com Io० ou mais), encontraram diferenças significativas:

[...] as empresas de maior porte demonstram melhor estrutura para desenvolvimento de aprendizagem organizacional, relacionada aos indicadores de desenvolvimento interno de especialistas, ao armazenamento de informações sobre os processos, à formalização da função de gerenciamento da informação e à coleta de dados. 
A escala desenvolvida por López, Peón e Ordás (2005) foi estruturada em quatro dimensões teóricas apoiadas nas propostas desenvolvidas por Huber (I99I), Slater e Narver (I995) e Tippins e Sohi (2003), e representativas dos seguintes mecanismos de aprendizagem organizacional: a) aquisição do conhecimento: ocorrida a partir de fontes externas e desenvolvimentos internos; b) distribuição: processo por meio do qual o conhecimento é estendido aos membros da organização; c) interpretação: por meio da qual os indivíduos compartilham e incorporam aspectos do conhecimento, obtendo uma compreensão compartilhada e coordenada em processos de tomada de decisão; d) memória organizacional: encarregada da guarda do conhecimento para uso futuro, apoiada por sistemas especialmente desenhados para esse propósito, ou por regras, procedimentos e/ou outros sistemas organizacionais.

Os dados coletados para a validação da escala foram levantados no nível organizacional em I95 companhias espanholas, e a mensuração da AO como uma variável latente de segunda ordem, composta pelas quatro dimensões já citadas, foi realizada por meio da modelagem em equações estruturais. Conforme citado, essa escala foi adaptada no Brasil por Isidro Filho (2007), com a coleta dos dados em uma única organização, participando da pesquisa 522 funcionários de uma instituição financeira. Utilizando a análise fatorial exploratória, esse autor identificou três fatores que divergem parcialmente dos quatro esperados, a saber: aquisição interna e externa de conhecimentos, compartilhamento de conhecimentos e codificação, e controle de conhecimentos.

Embora os instrumentos desenvolvidos por Templeton, Lewis e Snyder (2002) e López, Peón e Ordás (2005) tenham partido de arcabouços teóricos bastante similares, acabaram gerando um conjunto de itens diferenciados e alinhados aos objetivos da pesquisa desenvolvida pelos autores.

Apesar da importância desses trabalhos empíricos na busca da mensuração da aprendizagem organizacional, tais escalas não exploram como objetivo primeiro os possíveis relacionamentos entre os níveis individual (AI), grupal (AG) e organizacional (AO), objeto deste estudo. A base para essa discussão foi identificada no trabalho de Chan (2003), quando este analisa a inter-relação entre os três níveis da aprendizagem em um hospital australiano, utilizando um instrumento de medida por ele organizado e que foi respondido por 189 funcionários de diferentes categorias funcionais.

O instrumento elaborado por Chan (2003) partiu de escalas de mensuração da AI (SUJAN; WEITZ; KUMAR, I994), da AG (EDMONDSON, I996) e da AO (GOH; RICHARDS, I997). O instrumento é formado por 4I itens. A AI é medida por 9 itens. A AG é avaliada por meio de II itens que abrangem comportamentos de aprendizagem internos e externos. A aprendizagem interna ( 6 itens) 
engloba monitoramento da performance, teste de pressupostos, criação de novas possibilidades por parte dos times e a comunicação do conhecimento dentro de seus times, visando ao aprendizado. A aprendizagem externa (5 itens) envolve a busca de novas informações e obtenção de feedback sobre o trabalho. Busca-se aqui identificar como a nova informação é adquirida "de fora" do time e como o conhecimento é compartilhado com outros indivíduos e grupos de trabalho. A AO é mensurada por 2I itens que exploram cinco dimensões: clareza de propósito e missão (4 itens), comprometimento da liderança e delegação de poder (5 itens), práticas e recompensas ( 5 itens), transferência de conhecimento ( 4 itens), equipe de trabalho e solução de problemas em grupo ( 3 itens).

Os resultados encontrados mostraram-se congruentes com a literatura, detectando que a aprendizagem nos grupos de trabalho está relacionada à aprendizagem que ocorre nos níveis individual e organizacional. Entretanto, o nível individual não estava significativamente associado à aprendizagem organizacional, o que parece indicar que os times se constituem no nível fundamental quando se pensa no fenômeno da aprendizagem nas organizações. A menos que os grupos que funcionam no interior da organização aprendam, a organização não aprenderá.

A aprendizagem nos times ou grupos de trabalho aparece, conforme detectado no trabalho de Chan, Pearson e Entrekin (2003), como um importante determinante da competitividade e do desempenho organizacional, que depende fortemente da cooperação entre todos os níveis organizacionais. É possível imaginar que a aprendizagem nos grupos de trabalho está positivamente relacionada ao desempenho do time, hipótese testada no estudo de Chan, Pearson e Entrekin (2003), demonstrando relacionamento positivo entre essas variáveis. Além dessa comprovação, os resultados apontam que questionamentos contínuos a respeito dos processos de trabalho e o compartilhamento do conhecimento entre os membros do grupo melhoram a performance organizacional. Tanto o uso da aprendizagem reflexiva como as necessidades dos clientes e do mercado, a atenção ao ciclo de vida (mais curto) dos produtos, o desenvolvimento da tecnologia e os fatores sociais parecem constituir-se em aspectos que influenciam o desempenho organizacional.

Outra pesquisa que examinou a questão da relação entre diferentes níveis de aprendizagem é a de Chan, Lim e Keasberry (2003), que mediu duas hipóteses. A primeira propôs que a $\mathrm{AI}$ está positivamente relacionada à $\mathrm{AO}$, enquanto a segunda verificou que a $\mathrm{AG}$ está positivamente relacionada à $\mathrm{AO}$. Nesse caso, a amostra era composta de gestores que trabalhavam na cidade de Seria, em Brunei. Sendo Seria uma cidade voltada à produção de óleo combustível, tais gestores trabalhavam em departamentos governamentais, na Shell e em empre- 
sas privadas desse ramo de atividade. Embora as escalas para medir a AI e a AG tenham sido as mesmas utilizadas por Chan (2003), a medida da AO apoiou-se no instrumento desenvolvido por Baker e Sinkula (I999), organizado para estudar o fenômeno em executivos de várias indústrias nos Estados Unidos. Essa escala está focada em três construtos: comprometimento com a aprendizagem, visão compartilhada e "manter a mente aberta".

Novamente, a hipótese que previa o relacionamento entre a $\mathrm{AI}$ e a $\mathrm{AO}$ não apresentou resultado significativo. O relacionamento entre AG - verificada a partir da ideia de aprendizagem interna e externa de Edmondson (I999) - e AO - verificada a partir dos três construtos anteriormente especificados - foi parcialmente comprovado. Nesse caso, apenas o construto "visão compartilhada" mostrou-se associado à aprendizagem interna do time, enquanto a aprendizagem externa foi significativamente associada ao comprometimento, à visão compartilhada e ao construto denominado "manter a mente aberta".

Nos estudos nacionais, Bido et al. (2008) utilizaram o instrumento original de Chan (2003) para investigar o tema da relação entre os três níveis da aprendizagem. Realizaram a tradução do instrumento do inglês para o português do Brasil, seguindo os procedimentos de tradução reversa (back translation) e validação de conteúdo destes com professores universitários e profissionais da área a ser pesquisada. As respostas dos participantes foram registradas em uma escala Likert com cinco possibilidades de respostas, que variam de concordo totalmente (5) a discordo totalmente (I). Vale salientar que, diferentemente de Chan (2003), os autores brasileiros trataram a AO como uma variável latente de segunda ordem. Os resultados obtidos no estudo de Bido et al. (2008) são comparados com os resultados desta pesquisa na seção 4 .

Tendo em vista os resultados conseguidos por Bido et al. (2008), optou-se por utilizar essa escala no estudo ora apresentado.

Acredita-se que a pesquisa aqui desenvolvida possa ampliar a discussão do tema e aumentar a validade da escala para a realidade brasileira, na medida em que seus sujeitos são funcionários de uma indústria, constituindo-se num grupo diferente do estudo nacional anterior que teve como foco uma instituição financeira. Para tanto, os resultados da presente pesquisa são comparados com os de Chan (2003) e Bido et al. (2008).

\section{METODOLOGIA}

Nesta seção, são descritos os procedimentos utilizados para a coleta e análise dos dados. 


\subsection{A EMPRESA PESQUISADA E A COLETA DE DADOS}

Os respondentes, sujeitos da pesquisa, são funcionários de uma indústria de produtos plásticos, com atuação em seis países (Itália, Canadá, Estados Unidos, China, África do Sul, Brasil); o controle acionário da empresa no Brasil está nas mãos de uma família. Essa organização está presente no país há 37 anos, possui 96 funcionários, distribuídos em duas plantas industriais. A organização fabrica produtos envolvendo automação de linhas de produção industrial, tendo entre seus clientes as empresas montadoras de máquinas.

Do quadro de funcionários, foram escolhidos, para fazer parte deste estudo, os integrantes de uma planta com um total de 88 funcionários. Considerando o ambiente industrial e a não disponibilidade de internet para todos, o instrumento de coleta foi disponibilizado impresso aos funcionários. O período de coleta foi de duas semanas, com um comunicado intermediário para incentivar os respondentes. Coletaram-se 46 questionários válidos, com taxa de retorno de 52\%.

A amostra de 46 respondentes poderia ser considerada insuficiente pela regra empírica de dez casos por variável (HAIR JR. et al., 2005), já que o instrumento conta com 4I indicadores, porém eles possuem um estrutura predefinida, ou seja, 9 mensuram a AI, II a AG e 2I a AO. Além disso, a análise por meio da modelagem em equações estruturais com a estimação PLS (Partial Least Squares - Path Modeling) se baseia em correlações e regressões. Por isso, Chin e Newsted (I999, p. 314, 326-327) comentam que a definição do tamanho da amostra (análise $a$ priori) deveria se basear na porção do modelo de mensuração ou estrutural em que há a maior quantidade de preditores. Esses autores sugerem que, melhor do que se basear em regras empíricas, a análise do poder estatístico (power analysis) deveria ser conduzida (a posteriori).

Para a análise do poder estatístico, foi utilizado o software $\mathrm{G}^{*}$ Power 3 (BUCHNER et al., 2006), e adotaram-se os valores recomendados por Hair Jr. et al. (2005, p. 29-2I), ou seja, nível de significância de $5 \%$ e poder estatístico de $80 \%$. Dessa forma, para uma amostra de 46 casos, apenas correlações iguais ou superiores a 0,4 seriam detectadas como significantes.

No modelo estrutural, há dois preditores, seguindo as mesmas recomendações de Hair Jr. et al. (2005, p. 29-2I ). O G*Power 3 estimou que o valor mínimo de $\mathrm{R}^{2}$ detectável como significante é igual a I8\%, lembrando que um R2 de I3\% é classificado por Cohen (I977, p. 4I2-4I4) como médio e $26 \%$ como grande.

Na seção 4, novas análises de poder estatístico são conduzidas quando resultados não significantes foram obtidos.

O instrumento utilizado se baseou naquele referenciado no estudo de Bido et al., (2008) e está disponível com os autores. Na Tabela 2, são apresentadas as assertivas que o compõem. 


\subsection{ANÁLISE DOS DADOS}

Inicialmente, foi realizada a verificação de dados faltantes (missing values) e atípicos (outliers), e um respondente teve suas respostas eliminadas por haver deixado quatro questões em branco, o que corresponde a 9,7\% dos dados para esse sujeito. Outros quatro sujeitos não preencheram uma questão cada, e estas foram preenchidas pela média das respostas dos demais respondentes para as respectivas questões. Os itens com escala reversa tiveram as respostas recodificadas $(\mathrm{I} \rightarrow 5,2 \rightarrow 4,3 \rightarrow 3,4 \rightarrow 2$ e $5 \rightarrow$ I).

Para estimar as relações entre AI, AG e AO, usou-se a modelagem em equações estruturais com estimação PLS (Partial Least Squares), considerando os seguintes motivos: dados não normais, amostra insuficiente para estimação com Lisrel e comparabilidade com estudos anteriores.

Em um primeiro momento, foi avaliado o modelo de mensuração (validade convergente, discriminante e confiabilidade), retirando-se itens que possuíam baixas cargas fatoriais. Esse raciocínio é ilustrado pelo argumento de Pett, Lackey e Sullivan (2003) de que o desenvolvimento de uma escala envolve interesse mais direcionado aos construtos que aos itens usados para medi-los. A análise foi completada com a elaboração do modelo estrutural, que possibilitou a comparação com os resultados de Bido et al. (2008) e Chan (2003).

\section{APRESENTAÇÃO DOS RESULTADOS}

Nesta seção, os resultados relativos à caracterização da amostra - avaliação do modelo de mensuração (validade e confiabilidade dos construtos) e do modelo estrutural - são apresentados.

\subsection{DADOS DEMOGRÁFICOS}

Os dados demográficos identificados na pesquisa mostram que 89,1\% dos respondentes são do sexo masculino (4I respondentes), que a maioria $(60,9 \%)$ se encontra na faixa etária entre 3I e 50 anos de idade e que a amostra incluiu pessoas de distintos níveis hierárquicos, como é apresentado na Tabela I. 
- RAM - REVISTA DE ADMINISTRAÇÃO MACKENZIE, V. 11, N. 2 •

\section{TABELA I}

PERFIL DO RESPONDENTE

\begin{tabular}{|c|c|c|c|c|}
\hline \multicolumn{2}{|c|}{ VARIÁVEIS DEMOGRÁFICAS } & \multirow{2}{*}{$\begin{array}{c}\text { UNIVERSO } \\
78\end{array}$} & \multicolumn{2}{|c|}{ AMOSTRA } \\
\hline \multirow{3}{*}{ Gênero } & Masculino & & 41 & $53 \%$ \\
\hline & Feminino & 10 & 4 & $40 \%$ \\
\hline & Missing & & 1 & \\
\hline \multirow{8}{*}{ Faixa etária } & Até 20 anos & 6 & 2 & $33 \%$ \\
\hline & De 21 a 25 anos & 6 & 5 & $83 \%$ \\
\hline & De 26 a 30 anos & 11 & 4 & $36 \%$ \\
\hline & De 31 a 35 anos & 14 & 8 & $57 \%$ \\
\hline & De 36 a 40 anos & 13 & 9 & $69 \%$ \\
\hline & De 41 a 50 anos & 20 & 9 & $45 \%$ \\
\hline & Acima de 50 anos & 18 & 7 & $39 \%$ \\
\hline & Missing & & 2 & \\
\hline \multirow{4}{*}{ Escolaridade } & Segundo grau & 73 & 27 & $37 \%$ \\
\hline & Superior & 11 & 11 & $100 \%$ \\
\hline & Pós-graduação & 4 & 4 & $100 \%$ \\
\hline & Missing & & 4 & \\
\hline \multirow{4}{*}{ Nível hierárquico } & Administrativo & 27 & 13 & $48 \%$ \\
\hline & Nível técnico & 58 & 14 & $24 \%$ \\
\hline & Gerência & 3 & 2 & $67 \%$ \\
\hline & Missing & & 17 & \\
\hline
\end{tabular}

(continua) 


\section{TABELA I (CONTINUAÇÃO)}

\section{PERFIL DO RESPONDENTE}

\begin{tabular}{|c|c|c|c|c|}
\hline \multicolumn{2}{|c|}{ VARIÁVEIS DEMOGRÁFICAS } & \multirow{2}{*}{$\frac{\text { UNIVERSO }}{8}$} & \multicolumn{2}{|c|}{ AMOSTRA } \\
\hline \multirow{9}{*}{ Tempo de empresa } & Até 1 ano & & 4 & $50 \%$ \\
\hline & Acima de 1 até 4 anos & 10 & 4 & $40 \%$ \\
\hline & Acima de 4 até 7 anos & 21 & 6 & $29 \%$ \\
\hline & Acima de 7 até 10 anos & 8 & 6 & $75 \%$ \\
\hline & Acima de 10 até 13 anos & 16 & 8 & $50 \%$ \\
\hline & Acima de 13 até 16 anos & 12 & 4 & $33 \%$ \\
\hline & Acima de 16 anos & 13 & 11 & $85 \%$ \\
\hline & Missing & & 3 & \\
\hline & TOTAL & 88 & 46 & $52 \%$ \\
\hline
\end{tabular}

Fonte: Elaborada pelos autores com base nos dados coletados.

\subsection{AVALIAÇÃO DO MODELO DE MENSURAÇÃO}

A análise do modelo de mensuração deve preceder a análise das relações entre os construtos ou VL, e, para essa finalidade, foi analisada a validade convergente, a confiabilidade composta e a validade discriminante.

Todas as VL (de primeira e segunda ordens) apresentaram variância média extraída (average variance extracted - AVE) maior que 50\%, o que atinge os critérios de Chin (I998) e Hair Jr. et al. (2005 , p. 507-508) para a indicação da existência de validade convergente.

Chin (I998) recomenda que, em estudos desenhados por meio de equações estruturais, a avaliação da confiabilidade do construto seja feita pela confiabilidade composta e esteja acima de 0,7 . Todas as VL apresentaram confiabilidade igual ou superior a 0,75 , com exceção da VL equipe de trabalho e solução de problemas em grupo (ETSP), que apresentou uma confiabilidade de o,65, o que pode ser explicado pelo fato de estar sendo mensurada por apenas dois indicadores e um deles possuir carga fatorial não significante, como pode se observar na Tabela 2. Para futuras pesquisas, devem-se desenvolver mais indicadores para essa VL. 
- RAM - REVISTA DE ADMINISTRAÇÃO MACKENZIE, V. 11, N. 2

SÃO PAULO, SP • MAR./ABR. $2010 \bullet$ p. 68-95 • ISSN 1678-6971

\section{TABELA 2}

\section{MATRIZ DE CARGAS CRUZADAS}

\begin{tabular}{|c|c|c|c|c|c|c|c|c|c|c|c|}
\hline $\begin{array}{l}\text { VARIÁVEIS } \\
\text { LATENTES DE } \\
1^{\text {a ORDEM }}\end{array}$ & INDICADORES & 1 & 2 & 3 & 4 & 5 & 6 & 7 & 8 & 9 & VALOR P \\
\hline \multirow{3}{*}{$\begin{array}{l}\text { 1. Frequên- } \\
\text { cia da Al }\end{array}$} & $\begin{array}{l}\text { Al_1_rev) Não há muitas coisas novas para } \\
\text { aprender em meu trabalho. }\end{array}$ & 0,68 & 0,30 & 0,27 & 0,55 & 0,49 & 0,22 & 0,32 & 0,30 & 0,39 & 0,00054 \\
\hline & $\begin{array}{l}\text { Al_5) Eu passo grande parte do tempo } \\
\text { aprendendo novas abordagens no trabalho. }\end{array}$ & 0,73 & 0,25 & 0,29 & 0,04 & 0,45 & 0,41 & 0,32 & 0,47 & 0,15 & 0,00000 \\
\hline & $\begin{array}{l}\text { Al_6) Estou sempre aprendendo algo novo em } \\
\text { meu trabalho. }\end{array}$ & 0,81 & 0,22 & 0,34 & 0,24 & 0,55 & 0,50 & 0,48 & 0,32 & 0,40 & 0,00000 \\
\hline \multirow{6}{*}{$\begin{array}{l}\text { 2. Importân- } \\
\text { cia da Al }\end{array}$} & $\begin{array}{l}\text { Al_2) Para se tornar um bom funcionário/ } \\
\text { gestor é importante melhorar continuamente } \\
\text { as habilidades no trabalho. }\end{array}$ & 0,26 & 0,89 & 0,12 & 0,10 & 0,06 & 0,07 & $-0,06$ & $-0,07$ & $-0,06$ & 0,00000 \\
\hline & $\begin{array}{l}\text { Al_4) Para mim é importante aprender com } \\
\text { cada uma de minhas experiências no trabalho. }\end{array}$ & 0,22 & 0,63 & 0,07 & $-0,04$ & 0,00 & 0,14 & 0,01 & 0,12 & $-0,12$ & 0,00000 \\
\hline & $\begin{array}{l}\text { Al_7) Cometer erros faz parte do processo de } \\
\text { aprendizagem. }\end{array}$ & 0,22 & 0,59 & $-0,12$ & $-0,03$ & 0,00 & 0,00 & $-0,15$ & 0,05 & $-0,07$ & 0,00104 \\
\hline & $\begin{array}{l}\text { Al_8) Aprender como ser um melhor } \\
\text { funcionário/gestor é de fundamental } \\
\text { importância para mim. }\end{array}$ & 0,34 & 0,69 & 0,29 & 0,17 & 0,09 & 0,14 & $-0,02$ & 0,19 & $-0,09$ & 0,00000 \\
\hline & $\begin{array}{l}\text { Al_9) Algumas vezes eu dedico muito esforço } \\
\text { para aprender algo novo. }\end{array}$ & 0,18 & 0,70 & 0,21 & 0,28 & 0,09 & 0,23 & 0,02 & 0,00 & 0,02 & 0,00000 \\
\hline & Al_3) Tomar decisões difíceis me agrada. & (a) & & & & & & & & & \\
\hline \multirow{6}{*}{$\begin{array}{l}\text { 3. Compor- } \\
\text { tamento } \\
\text { interno } \\
\text { da AG }\end{array}$} & $\begin{array}{l}\text { AG_10) Em nossa equipe, as pessoas discutem } \\
\text { maneiras de prevenir e aprender com os erros. }\end{array}$ & 0,25 & 0,05 & 0,80 & 0,25 & 0,48 & 0,46 & 0,48 & 0,33 & 0,16 & 0,00000 \\
\hline & $\begin{array}{l}\text { AG_11) Nossa equipe frequentemente dedica } \\
\text { tempo para descobrir maneiras de melhorar } \\
\text { nossos processos de trabalho. }\end{array}$ & 0,39 & 0,15 & 0,81 & 0,48 & 0,52 & 0,47 & 0,42 & 0,49 & 0,28 & 0,00000 \\
\hline & $\begin{array}{l}\text { AG_14) Em minha equipe, alguém sempre } \\
\text { se certifica de que refletimos sobre o nosso } \\
\text { processo de trabalho. }\end{array}$ & 0,44 & 0,16 & 0,72 & 0,41 & 0,56 & 0,43 & 0,40 & 0,35 & 0,40 & 0,00000 \\
\hline & $\begin{array}{l}\text { AG_15) Em minha equipe, as pessoas } \\
\text { frequentemente argumentam sobre assuntos } \\
\text { em pauta. }\end{array}$ & 0,05 & 0,16 & 0,60 & 0,22 & 0,24 & 0,36 & 0,26 & 0,46 & 0,15 & 0,00324 \\
\hline & $\begin{array}{l}\text { AG_12_rev) Os problemas e os erros de } \\
\text { nossa equipe nunca são comunicados aos } \\
\text { responsáveis de modo que ações corretivas } \\
\text { possam ser tomadas. }\end{array}$ & (a) & & & & & & & & & \\
\hline & $\begin{array}{l}\text { AG_13_rev) Minha equipe lida com as } \\
\text { diferenças de opiniões particularmente e não } \\
\text { em público. }\end{array}$ & (a) & & & & & & & & & \\
\hline \multirow{2}{*}{$\begin{array}{l}\text { 4. Compor- } \\
\text { tamento } \\
\text { externo } \\
\text { da AG }\end{array}$} & $\begin{array}{l}\text { AG_16) Minha equipe frequentemente } \\
\text { coopera com outras equipes para alcançar os } \\
\text { objetivos organizacionais. }\end{array}$ & 0,29 & 0,08 & 0,33 & 0,79 & 0,39 & 0,30 & 0,35 & 0,26 & 0,40 & 0,00000 \\
\hline & $\begin{array}{l}\text { AG_17) Minha equipe mantém a organização } \\
\text { informada a respeito do que planejamos } \\
\text { executar. }\end{array}$ & 0,16 & 0,16 & 0,38 & 0,73 & 0,29 & 0,26 & 0,16 & 0,09 & 0,34 & 0,00000 \\
\hline
\end{tabular}




\section{TABELA 2 (CONTINUAC̣ÃO)}

\section{MATRIZ DE CARGAS CRUZADAS}

\begin{tabular}{|c|c|c|c|c|c|c|c|c|c|c|c|}
\hline $\begin{array}{l}\text { VARIÁVEIS } \\
\text { LATENTES DE } \\
1^{\text {a ORDEM }}\end{array}$ & INDICADORES & 1 & 2 & 3 & 4 & 5 & 6 & 7 & 8 & 9 & VALOR P \\
\hline \multirow{3}{*}{$\begin{array}{l}\text { 4. Compor- } \\
\text { tamento } \\
\text { externo } \\
\text { da AG }\end{array}$} & $\begin{array}{l}\text { AG_19) Convidamos pessoas de fora da } \\
\text { nossa equipe para apresentar informações ou } \\
\text { debater conosco assuntos de interesse. }\end{array}$ & 0,39 & 0,12 & 0,40 & 0,66 & 0,52 & 0,35 & 0,31 & 0,34 & 0,42 & 0,00012 \\
\hline & $\begin{array}{l}\text { AG_20_rev) Não temos tempo para informar } \\
\text { as pessoas de fora da nossa equipe sobre os } \\
\text { nossos projetos. }\end{array}$ & 0,22 & 0,03 & 0,24 & 0,68 & 0,34 & 0,16 & 0,17 & & & \\
\hline & $\begin{array}{l}\text { AG_18) As pessoas de minha equipe obtêm } \\
\text { informações para o trabalho a partir de outras } \\
\text { fontes, tais como clientes ou outras unidades } \\
\text { da organização. }\end{array}$ & & & & & & & & & & \\
\hline \multirow{4}{*}{$\begin{array}{l}\text { 5. Clareza } \\
\text { de pro- } \\
\text { pósito e } \\
\text { missão } \\
\text { (CPM) }\end{array}$} & $\begin{array}{l}\text { CPM_22_rev) Eu não entendo como a missão } \\
\text { da organização pode ser alcançada. }\end{array}$ & 0,29 & $-0,24$ & 0,47 & 0,30 & 0,65 & 0,32 & 0,47 & 0,28 & 0,42 & 0,00001 \\
\hline & $\begin{array}{l}\text { CPM_23) A missão da organização identifica } \\
\text { os valores aos quais todos os funcionários } \\
\text { devem se adequar. }\end{array}$ & 0,55 & 0,01 & 0,41 & 0,52 & 0,80 & 0,36 & 0,50 & 0,32 & 0,42 & 0,00000 \\
\hline & $\begin{array}{l}\text { CPM_24) Nesta organização, os funcionários } \\
\text { têm oportunidades de autoavaliação com } \\
\text { relação ao alcance de metas. }\end{array}$ & 0,67 & 0,29 & 0,57 & 0,43 & 0,86 & 0,64 & 0,67 & 0,53 & 0,43 & 0,00000 \\
\hline & $\begin{array}{l}\text { CPM_21) Há amplo apoio e aceitação dos } \\
\text { funcionários sobre a missão da organização. }\end{array}$ & (a) & & & & & & & & & \\
\hline \multirow{5}{*}{$\begin{array}{l}\text { 6. Com- } \\
\text { prometi- } \\
\text { mento da } \\
\text { liderança } \\
\text { e dele- } \\
\text { gação } \\
\text { de poder } \\
\text { (CLDP) }\end{array}$} & $\begin{array}{l}\text { CLDP_26) Diretores e funcionários da } \\
\text { organização compartilham uma visão comum } \\
\text { sobre o que devemos realizar em nosso } \\
\text { trabalho. }\end{array}$ & 0,46 & 0,22 & 0,53 & 0,52 & 0,84 & 0,84 & 0,70 & 0,60 & 0,46 & 0,00000 \\
\hline & $\begin{array}{l}\text { CLDP_27) Nesta organização, os gestores } \\
\text { aceitam críticas sem serem defensivos demais. }\end{array}$ & 0,30 & $-0,07$ & 0,36 & 0,04 & 0,72 & 0,72 & 0,56 & 0,57 & 0,29 & 0,00000 \\
\hline & $\begin{array}{l}\text { CLDP_28) Nesta organização, os gestores } \\
\text { frequentemente dão feedbacks úteis } \\
\text { que ajudam a identificar problemas e } \\
\text { oportunidades potenciais. }\end{array}$ & 0,45 & 0,27 & 0,39 & 0,16 & 0,63 & 0,63 & 0,39 & 0,44 & 0,11 & 0,00004 \\
\hline & $\begin{array}{l}\text { CLDP_29) Nesta organização, os gestores } \\
\text { frequentemente envolvem os funcionários em } \\
\text { decisões importantes. }\end{array}$ & 0,36 & 0,09 & 0,48 & 0,36 & 0,83 & 0,83 & 0,70 & 0,55 & 0,38 & 0,00000 \\
\hline & $\begin{array}{l}\text { CLDP_25_rev) Os diretores da organização } \\
\text { resistem à mudança e têm medo de ideias } \\
\text { novas. }\end{array}$ & (a) & & & & & 0,43 & & & & \\
\hline \multirow{2}{*}{$\begin{array}{l}\text { 7. Práticas } \\
\text { e recom- } \\
\text { pensas } \\
\text { (PR) }\end{array}$} & $\begin{array}{l}\text { PR_30) Eu posso propor com frequência } \\
\text { novas ideias para a organização. }\end{array}$ & 0,16 & 0,06 & 0,37 & 0,23 & 0,43 & 0,59 & 0,52 & 0,25 & 0,20 & 0,00403 \\
\hline & $\begin{array}{l}\text { PR_31) Pela minha experiência, os novos } \\
\text { funcionários nesta organização são } \\
\text { encorajados a questionar o modo como as } \\
\text { coisas são feitas. }\end{array}$ & 0,64 & 0,06 & 0,48 & 0,39 & 0,59 & 0,67 & 0,83 & 0,48 & 0,49 & 0,00000 \\
\hline
\end{tabular}


- RAM - REVISTA DE ADMINISTRAÇÃO MACKENZIE, V. 11, N. 2

SÃO PAULO, SP • MAR./ABR. 2010 • p. 68-95 • ISSN 1678-6971

\section{TABeLA 2 (ConClus Ão)}

\section{MATRIZ DE CARGAS CRUZADAS}

\begin{tabular}{|c|c|c|c|c|c|c|c|c|c|c|c|}
\hline $\begin{array}{l}\text { VARIÁVEIS } \\
\text { LATENTES DE } \\
1^{\text {a ORDEM }}\end{array}$ & INDICADORES & 1 & 2 & 3 & 4 & 5 & 6 & 7 & 8 & 9 & VALOR P \\
\hline \multirow{3}{*}{$\begin{array}{l}\text { 7. Práticas } \\
\text { e recom- } \\
\text { pensas } \\
\text { (PR) }\end{array}$} & $\begin{array}{l}\text { PR_32) Nesta organização, os gestores } \\
\text { encorajam os funcionários a experimentar } \\
\text { com o objetivo de melhorar os processos de } \\
\text { trabalho. }\end{array}$ & 0,49 & $-0,05$ & 0,57 & 0,42 & 0,67 & 0,71 & 0,88 & 0,53 & 0,55 & 0,00000 \\
\hline & $\begin{array}{l}\text { PR_33) Ideias inovadoras que funcionam são } \\
\text { frequentemente recompensadas pela direção } \\
\text { da empresa. }\end{array}$ & 0,23 & $-0,07$ & 0,37 & 0,05 & 0,71 & 0,49 & 0,80 & 0,63 & 0,36 & 0,00000 \\
\hline & $\begin{array}{l}\text { PR_34_rev) Pela minha experiência, as novas } \\
\text { ideias dos funcionários não são tratadas } \\
\text { seriamente pela direção da organização. }\end{array}$ & 0,19 & $-0,23$ & 0,11 & 0,19 & 0,49 & 0,49 & 0,61 & 0,20 & 0,33 & 0,00002 \\
\hline \multirow{4}{*}{$\begin{array}{l}\text { 8. Transfe- } \\
\text { rência de } \\
\text { conhe- } \\
\text { cimento } \\
\text { (TC) }\end{array}$} & $\begin{array}{l}\text { TC_35) Eu frequentemente converso com } \\
\text { pessoas de outras áreas sobre programas ou } \\
\text { atividades de trabalho bem-sucedidas para } \\
\text { compreender a razão do sucesso desses. }\end{array}$ & 0,25 & $-0,09$ & 0,40 & 0,40 & 0,49 & 0,60 & 0,35 & 0,72 & 0,31 & 0,00000 \\
\hline & $\begin{array}{l}\text { TC_37) Os novos processos de trabalho que } \\
\text { podem ser úteis para a organização como } \\
\text { um todo, são usualmente compartilhados } \\
\text { com todos os funcionários. }\end{array}$ & 0,42 & 0,18 & 0,41 & 0,14 & 0,60 & 0,60 & 0,57 & 0,81 & 0,36 & 0,00000 \\
\hline & $\begin{array}{l}\text { TC_38) Nesta organização temos um sistema } \\
\text { que permite a aprendizagem de práticas } \\
\text { bem-sucedidas de outras organizações. }\end{array}$ & 0,36 & 0,04 & 0,37 & 0,10 & 0,40 & 0,40 & 0,32 & 0,59 & 0,20 & 0,00209 \\
\hline & $\begin{array}{l}\text { TC_36_rev) As falhas raramente são } \\
\text { discutidas de forma construtiva em nossa } \\
\text { organização. }\end{array}$ & (a) & & & & & & & & & \\
\hline \multirow{3}{*}{$\begin{array}{l}\text { 9. Equipe de } \\
\text { trabalho } \\
\text { e solução } \\
\text { de pro- } \\
\text { blemas } \\
\text { em grupo } \\
\text { (ETSP) }\end{array}$} & $\begin{array}{l}\text { ETSP_39) A atual prática organizacional } \\
\text { encoraja os funcionários a resolverem juntos } \\
\text { os problemas, antes de discuti-los com seu } \\
\text { gestor. }\end{array}$ & 0,29 & $-0,17$ & 0,34 & 0,54 & 0,46 & 0,44 & 0,54 & 0,38 & 0,94 & 0,00000 \\
\hline & $\begin{array}{l}\text { ETSP_41) Nesta organização, as equipes } \\
\text { voltadas à solução de problemas } \\
\text { caracterizam-se por ter funcionários de } \\
\text { várias áreas funcionais. }\end{array}$ & 0,46 & 0,18 & 0,09 & 0,16 & 0,35 & 0,07 & 0,15 & 0,19 & 0,41 & 0,25468 \\
\hline & $\begin{array}{l}\text { ETSP_40_rev) Nós raramente criamos } \\
\text { equipes informais para resolver problemas } \\
\text { organizacionais. }\end{array}$ & (a) & & & & & & & & & \\
\hline
\end{tabular}

(a) = item eliminado do modelo de mensuração por apresentar cargas fatoriais muito abaixo do mínimo recomendado.

Itens com o sufixo “_rev” tiveram sua escala invertida ( $\rightarrow 5 ; 2 \rightarrow 4$ etc.) antes de qualquer análise.

Fonte: Elaborada pelos autores com base nos dados coletados. 
O fato de os indicadores possuírem cargas mais altas em suas VL do que em qualquer outra VL é um indicativo de que há validade discriminante, novamente com exceção de um dos indicadores da VL ETSP, que apresentou carga fatorial não significante.

Outro critério sugerido por Chin (I998) é apresentado na Tabela 3, em que se observa que as correlações apresentadas entre as variáveis latentes são menores que a raiz quadrada da $\mathrm{AVE}$ (indicadores têm relação mais forte com sua VL do que com as outras VL), confirmando a validade discriminante. Uma exceção foi a correlação entre PR e CLDP, que foi superior à raiz quadrada da AVE, sugerindo a falta de validade discriminante entre elas, o que, no presente modelo, não é um problema, já que ambas as VL foram usadas como indicadores reflexivos do mesmo construto, a aprendizagem organizacional.

TABELA 3

CORRELAÇÃO DE PEARSON E ESTATÍSTICAS

DESCRITIVAS DAS VARIÁVEIS LATENTES (VL)

\begin{tabular}{|c|c|c|c|c|c|c|c|c|c|}
\hline VL DE $1^{\text {a }}$ ORDEM & 1 & 2 & 3 & 4 & 5 & 6 & 7 & 8 & 9 \\
\hline 1. Frequência da Al & 0,74 & & & & & & & & \\
\hline 2. Importância da Al & 0,34 & 0,71 & & & & & & & \\
\hline 3. Comportamento interno da AG & 0,41 & 0,18 & 0,74 & & & & & & \\
\hline 4. Comportamento externo da AG & 0,38 & 0,14 & 0,47 & 0,71 & & & & & \\
\hline 5. Clareza de propósito e missão (CPM) & 0,67 & 0,07 & 0,63 & 0,54 & 0,78 & & & & \\
\hline $\begin{array}{l}\text { 6. Comprometimento da liderança e } \\
\text { delegação de poder (CLDP) }\end{array}$ & 0,51 & 0,16 & 0,58 & 0,38 & 0,59 & 0,76 & & & \\
\hline 7. Práticas e recompensas (PR) & 0,50 & $-0,05$ & 0,54 & 0,35 & 0,72 & 0,79 & 0,74 & & \\
\hline 8. Transferência de conhecimento (TC) & 0,49 & 0,08 & 0,55 & 0,30 & 0,50 & 0,71 & 0,60 & 0,71 & \\
\hline $\begin{array}{l}\text { 9. Equipe de trabalho e solução de } \\
\text { problemas em grupo (ETSP) }\end{array}$ & 0,43 & $-0,09$ & 0,35 & 0,55 & 0,54 & 0,43 & 0,54 & 0,41 & 0,72 \\
\hline Média & 3,4 & 4,2 & 3,1 & 3,2 & 3,0 & 2,6 & 2,7 & 3,0 & 2,8 \\
\hline Mediana & 3,4 & 4,2 & 3,3 & 3,3 & 3,0 & 2,6 & 2,8 & 3,2 & 2,6 \\
\hline Desvio padrão & 0,84 & 0,54 & 0,91 & 0,95 & 0,95 & 0,91 & 0,90 & 0,92 & 0,86 \\
\hline
\end{tabular}




\section{TABELA 3 (CONTINUAC̣ÃO)}

CORRELAÇÃO DE PEARSON E ESTATÍSTICAS

DESCRITIVAS DAS VARIÁVEIS LATENTES (VL)

\begin{tabular}{rccc}
\hline VL DE $2^{\text {a ORDEM - MODELO ESTRUTURAL }}$ & 1 & 2 & 3 \\
\hline 1 - Aprendizagem Individual (AI) & 0,82 & & \\
\hline 2 - Aprendizagem Grupal (AG) & 0,39 & 0,86 & \\
\hline 3 - Aprendizagem Organizacional (AO) & 0,38 & 0,67 & 0,82 \\
\hline Média & 4,0 & 3,1 & 2,8 \\
\hline Mediana & 4,0 & 3,2 & 2,7 \\
\hline Desvio padrão & 0,52 & 0,80 & 0,78 \\
\hline
\end{tabular}

Nota: Os valores em negrito (na diagonal) são a raiz quadrada da AVE. As médias, as medianas e os desvios padrão foram calculados com os escores obtidos na estimação do modelo com o software SmartPLS 2.0.M3 (RINGLE; WENDE; WILL, 2005). As VL de segunda ordem apresentaram validade discriminante de acordo com esse critério.

Fonte: Elaborada pelos autores com base nos dados coletados.

\subsection{AVALIAÇÃO DO MODELO ESTRUTURAL}

O modelo estrutural diz respeito às relações entre as variáveis latentes AI, AG e AO. Considerando o modelo apresentado na Figura I, em que AI e AG foram utilizadas como preditoras da AO, obtiveram-se as correlações apresentadas nas tabelas 2 e 4 e os resultados da Tabela 4 , em que se destaca a predominância da relação entre AG e AO. 


\section{FigurA I}

\section{MODELO ESTRUTURAL E DE MENSURAÇÃO DOS FATORES DE SEGUNDA ORDEM}

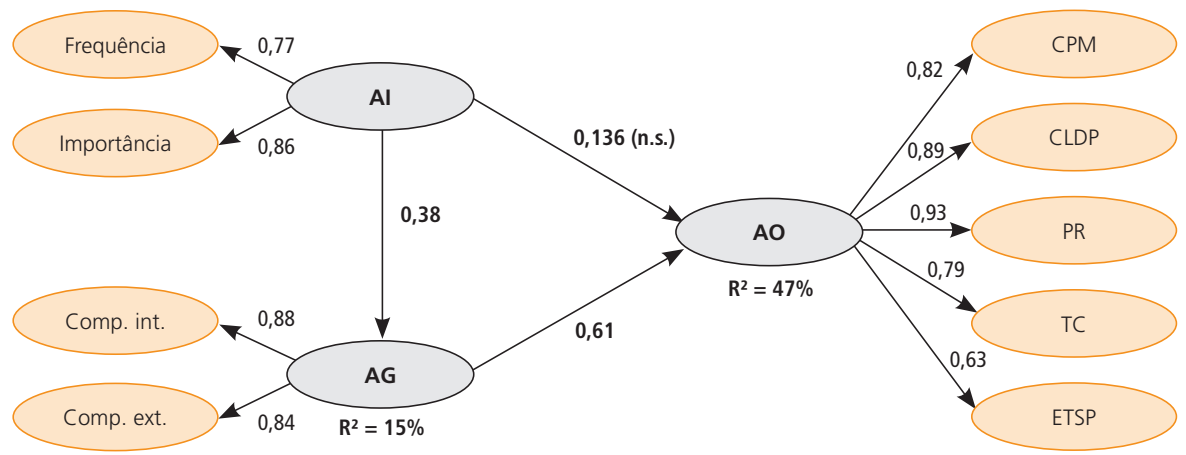

Nota: Utilizou-se o software SmartPLS 2.0.M3 (RINGLE; WENDE; WILL, 2005). Todos os coeficientes estão na forma padronizada e são altamente significantes $(\mathrm{p}<0, \mathrm{OI})$, com exceção do coeficiente entre AI e AO. A significância foi estimada por meio de bootstrap com N $=46$ e I.000 repetições. Para não tornar a figura muito complexa, omitiram-se os indicadores, porém suas cargas fatoriais estão na Tabela 2.

Comp. int. = comportamentos internos da AG; Comp. ext. = comportamentos externos da AG; $\mathrm{CPM}=$ clareza de propósito e missão; CLDP = comprometimento da liderança e delegação de poder; $\mathrm{PR}=$ práticas e recompensas; $\mathrm{TC}$ = transferência de conhecimento; $\mathrm{ETSP}=$ equipe de trabalho e solução de problemas em grupo; $\mathrm{AI}=$ aprendizagem individual; $\mathrm{AG}=$ aprendizagem grupal (AG); $\mathrm{AO}=$ aprendizagem organizacional.

Fonte: Elaborada pelos autores com base nos dados coletados.

\section{TABELA 4}

COMPARAÇÃO ENTRE OS COEFICIENTES ESTRUTURAIS E R² DOS TRÊS ESTUDOS

\begin{tabular}{|c|c|c|c|c|}
\hline & ESTUDO & Chan (2003) & Bido et al. (2008) & Resultados atuais \\
\hline & ORGANIZAÇÃO & $\begin{array}{c}\text { Hospital } \\
\text { australiano }\end{array}$ & $\begin{array}{l}\text { Instituição } \\
\text { financeira }\end{array}$ & $\begin{array}{l}\text { Indústria de } \\
\text { produtos plásticos }\end{array}$ \\
\hline \multirow{2}{*}{$R^{2}$} & $A G$ & $6 \%$ & $9 \%$ & $15 \%$ \\
\hline & $\mathrm{AO}$ & $24 \%-38 \%(a)$ & $41 \%$ & $47 \%$ \\
\hline \multirow{3}{*}{$\begin{array}{l}\text { COEFICIENTE } \\
\text { ESTRUTURAL }\end{array}$} & $\mathrm{Al} \rightarrow \mathrm{AG}$ & - & $0,301 * *$ & $0,387 * *$ \\
\hline & $\mathrm{Al} \rightarrow \mathrm{AO}$ & n.s. & 0,400 ** & 0,136 (n.s.) \\
\hline & $\mathrm{AG} \rightarrow \mathrm{AO}$ & - & $0,395 * *$ & 0,618 ** \\
\hline
\end{tabular}

Nota (a): Chan (2003) utilizou as cinco dimensões da AO separadamente.

$* * \mathrm{p}<0$, OI.

Fonte: Elaborada pelos autores com base nos dados coletados. 
Apesar de o método de análise ter sido semelhante ao utilizado por Bido et al. (2008) para permitir a comparabilidade de resultados, o resultado não significante da relação entre AI e AO poderia ter sido causado pela multicolinearidade, observando-se que, mesmo quando a multicolinearidade é baixa $(\mathrm{VIF}=\mathrm{I}, 33$ ), Cohen et al. (2003, p. 42I) encontraram efeito semelhante. Por isso, decidiu-se comparar as correlações entre as VL, o que é feito na Tabela 5.

\section{TABELA 5}

\section{COMPARAÇÃO ENTRE AS CORRELAÇÕES E} MÉDIAS DOS TRÊS ESTUDOS

\begin{tabular}{|c|c|c|c|c|c|c|c|c|c|}
\hline \multirow[b]{2}{*}{$\begin{array}{l}\text { VL DE 2a ORDEM - } \\
\text { MODELO ESTRUTURAL }\end{array}$} & \multicolumn{3}{|c|}{ CHAN (2003) } & \multicolumn{3}{|c|}{ BIDO ET AL. (2008) } & \multicolumn{3}{|c|}{ RESULTADOS ATUAIS } \\
\hline & Al & AG & AO & Al & AG & AO & Al & AG & $\mathrm{AO}$ \\
\hline $\begin{array}{l}\text { Aprendizagem } \\
\text { Individual (Al) }\end{array}$ & 1 & & & 1 & & & 1 & & \\
\hline $\begin{array}{l}\text { Aprendizagem } \\
\text { Grupal (AG) }\end{array}$ & 0,28 & 1 & & 0,30 & 1 & & $0,39 * *$ & 1 & \\
\hline $\begin{array}{l}\text { Aprendizagem } \\
\text { Organizacional (AO) }\end{array}$ & $\begin{array}{l}0,28 \\
\text { (a) }\end{array}$ & $\begin{array}{l}0,56 \\
\text { (a) }\end{array}$ & 1 & 0,52 & 0,52 & 1 & $0,38^{*}$ & $0,67^{* *}$ & 1 \\
\hline Média & $\begin{array}{l}4,1 \\
\text { (b) }\end{array}$ & $\begin{array}{l}3,3 \\
\text { (b) }\end{array}$ & $\begin{array}{l}3,2 \\
\text { (c) }\end{array}$ & 3,5 & 3,7 & 2,8 & 4,0 & 3,1 & 2,8 \\
\hline Mediana & - & - & - & 3,5 & 3,7 & 2,8 & 4,0 & 3,2 & 2,7 \\
\hline Desvio padrão & - & - & - & 0,42 & 0,51 & 0,48 & 0,52 & 0,80 & 0,78 \\
\hline
\end{tabular}

Nota (a): Correlação calculada pela média das correlaç̧̃es com as dimensões da AO.

Nota (b): A escala usada por Chan (2003) variava de i a 7 , mas, para permitir a comparabilidade, as médias foram transformadas proporcionalmente para a escala de i a 5 .

Nota (c): A média das cinco dimensões da AO foi usada como média da AO e depois transformada para a escala de i a 5 .

$* \mathrm{p}<0,05$.

$* * \mathrm{p}<0$, OI.

Fonte: Elaborada pelos autores com base nos dados coletados.

Todas as correlações foram comparadas duas as duas, de acordo com o teste proposto por Cohen et al. (2003, p. 49), e a única diferença apontada como significante $(p<0,05)$ foi a correlação entre AI e AO nos estudos de Chan (2003) 
$-0,28$ - e Bido et al. (2008) - 0,52. Para todas as demais comparações, as diferenças não foram significantes. Entretanto, se fosse considerada a correção de Bonferroni, já que foram realizadas comparações múltiplas, o valor crítico a ser usado deveria ser 0,0056 , que corresponde a $5 \%$ dividido por 9 , e a diferença encontrada não seria considerada significante $(\mathrm{p}=0,0$ I9).

Para avaliar se esses resultados não significantes se deveram ao reduzido tamanho amostral (apesar de representar 63,8\% da população de interesse), foi elaborada a Tabela 6 , na qual se observa que as diferenças são consideradas pequenas na classificação de Cohen et al. (2003) e que mesmo amostras maiores não as detectariam como significantes.

\section{TABELA 6}

TESTE DE IGUALDADE DAS CORRELAÇÕES

\begin{tabular}{lcc}
\hline COMPARANDO AS CORRELAÇÕES & VALOR Z (A) & EFEITO (B) \\
\hline AG-Al (Chan 0,28 - Bido 0,30) & $-0,18$ & 0,02 \\
AG-Al (Chan 0,28 - Atual 0,39) & $-0,73$ & 0,12 \\
AG-Al (Bido 0,30 - Atual 0,39) & $-0,56$ & 0,10 \\
\hline AO-Al (Chan 0,28 - Bido 0,52) & $-2,34$ & $\mathbf{0 , 2 9}(\mathbf{c})$ \\
AO-Al (Chan 0,28 - Atual 0,38) & $-0,66$ & 0,11 \\
AO-Al (Bido 0,52 - Atual 0,38) & 0,97 & 0,18 \\
AG-AO (Chan 0,56 - Bido 0,52) & 0,46 & 0,06 \\
AG-AO (Chan 0,56 - Atual 0,67) & $-1,05$ & 0,18 \\
AG-AO (Bido 0,52 - Atual 0,67) & $-1,29$ & 0,23 (d) \\
\hline
\end{tabular}

Nota (a): Teste de acordo com Cohen et al. (2003, p. 49), valores z acima de I,96 são significantes a $5 \%$.

Nota (b): As análises do tamanho do efeito e do poder estatístico foram realizadas com o software G*Power 3 (BUCHNER et al., 2006) e confirmadas por meio do procedimento de Cohen (I977, p. IIO). Efeitos da ordem de O,I são considerados pequenos, ०,3 médios e o,5 grandes (BUCHNER et al., 2006; COHEN, I977, p. II5).

Nota (c): Para um nível de significância de 5\% e amostras dadas, o poder estatístico foi de o,65.

Nota (d): Para que essa diferença fosse detectada como significante ao nível de $5 \%$ de significância e 0,8 de poder estatístico, a presente pesquisa deveria ter uma amostra superior a 999.999.999 casos ou 5.400 casos para um poder estatístico de 0,65 . De onde se conclui que as diferenças entre as correlações (tamanho do efeito) são, realmente, pequenas.

Fonte: Elaborada pelos autores com base nos dados coletados. 


\section{DISCUSSÃO dOS RESULTADOS}

De certa forma, esses resultados foram inesperados, porque um dos motivos para coletar os dados em uma indústria era justamente a expectativa de que os resultados seriam diferentes daqueles obtidos no hospital (CHAN, 2003) e na instituição financeira (BIDO et al., 2008).

Apesar disso, observaram-se várias semelhanças entre os três resultados. Por exemplo, a relação de AI com AG e AO, de modo geral, foi baixa nos três estudos (correlação entre 0,28 e 0,39), com exceção da correlação entre AI e AO no estudo de Bido et al. (2008), que atingiu um valor de 0,52. Infelizmente, não há informações sobre os processos da instituição bancária pesquisada para identificar as causas dessa associação mais forte, mas uma especulação razoável é que, tanto no hospital quanto na indústria, a atuação em grupos seria mais destacada do que na instituição financeira, em que boa parte do trabalho pode ser efetuada individual ou impessoalmente, por exemplo, por acesso remoto (intranet e assemelhados).

Ainda em relação às correlações, observa-se que a correlação entre AG e AO foi a mais alta nas três pesquisas. Uma explicação para esse resultado pode estar associada à percepção dos respondentes de que o comportamento da equipe seja realmente o "portão de entrada" para a AO.

Do ponto de vista prático, é interessante notar que a AI apresentou os valores médios mais altos nos três estudos (Tabela 5), indicando que os respondentes, além de considerarem importante o aprendizado de rotinas/abordagens novas para o seu desenvolvimento como profissional, percebem que têm tido oportunidades para esse aprendizado.

Por sua vez, a AO recebeu as menores médias (Tabela 5), com valores muito próximos de 3, em uma escala de i a 5. Na Tabela 3, é possível observar que as dimensões com valores abaixo de 3 , na presente pesquisa, foram: "Comprometimento da liderança e delegação de poder", "Práticas e recompensas" e "Equipe de trabalho e solução de problemas". Portanto, essas dimensões poderiam ser priorizadas em ações para melhorias dos processos relacionados à $\mathrm{AO}$ na empresa pesquisada.

Respondendo ao objetivo complementar, o instrumento se mostrou válido e confiável de um modo geral, apenas a dimensão da AO "Equipe de trabalho e solução de problemas em grupo (ETSP)" necessita de um aperfeiçoamento (elaboração de mais indicadores), porque foi mensurada por apenas dois indicadores e um deles não apresentou carga fatorial significante. 


\section{CONCLUSÕES}

Apesar de a amostra da presente pesquisa ter sido de apenas 46 sujeitos, o que pode ser considerado pequeno em termos absolutos, ela representa $63,8 \%$ do total de funcionários de uma indústria de produtos plásticos. Além disso, a análise do poder estatístico mostrou que as diferenças não significantes se devem, de fato, à pequena magnitude dessas diferenças e não ao tamanho amostral (em valor absoluto) reduzido. Acrescenta-se ainda que a comparação dos resultados obtidos nessa amostra com os resultados anteriores obtidos em um hospital (CHAN, 2003) e em uma instituição financeira (BIDO et al., 2008) fortaleceu a confiança na conclusão de que AI, AG e AO são correlacionadas, mas AG e AO mais fortemente.

Embora a relação entre AG e AO tenha apresentado efeito direto com a maior carga estrutural (0,6I8), a relação entre AI e AG também foi significativa $(0,387)$, revelando que AI apresenta efeitos indiretos sobre AO. Esse resultado remete ao trabalho de Friedman (200I), que examina o papel dos indivíduos como agentes da $\mathrm{AO}$, destacando que um conjunto de atributos favorece e possibilita que determinadas pessoas nas organizações sejam promotoras de AO. Tais atributos, complexos e, por vezes, contraditórios, envolvem: a) ser proativo, mas também reflexivo; b) ter altas aspirações, mas ser realista a respeito de suas limitações; c) ser crítico e, ao mesmo tempo, comprometido com a organização; d) ser independente e cooperativo com os outros. Esse autor adverte que os dados empíricos a esse respeito apontam que os indivíduos possuidores desse conjunto de atributos são raros e nem sempre conseguem transformar suas aprendizagens individuais em ganhos organizacionais. É fato que os indivíduos, em todos os níveis organizacionais, desenvolvem novas ideias, trabalham sobre seus erros e resolvem problemas, atividades estas que se constituem em oportunidades para aprender. No entanto, nem todos escolhem agir a partir dessas descobertas individuais e chamar atenção da organização sobre elas e seu potencial para uma melhoria de desempenho. Entende-se que esse papel envolve riscos e faz que os possíveis agentes individuais da aprendizagem estejam cientes dos conflitos e das resistências que deverão enfrentar, pois nem sempre suas iniciativas serão entendidas como benéficas para a organização. Friedman (200I) adverte a respeito da necessidade de treinamento e suporte adequados para que as pessoas possam se constituir em agentes da AO. Nesse sentido, parece possível reconhecer que a passagem da AI para AO constitui-se num processo bastante complexo e menos visível no âmbito organizacional, daí seu efeito menos significativo e indireto encontrado nos dados empíricos da pesquisa aqui apresentada. 
Os resultados parecem ainda dar suporte à ideia de que é preciso "olhar" a aprendizagem organizacional de forma mais holística e integrada, a partir de sua natureza coletiva, conforme recomendam os autores da perspectiva social (EASTERBY-SMITH; ARAUJO, 200I). Quanto à importância do grupo nesse processo, o estudo reforçou o destaque que autores como Pawlowsky (200I) e Edmondson (I996) atribuem ao grupo ou time como espaço social privilegiado para o compartilhamento das experiências e dos modelos mentais, tão necessários ao processo de aprender.

Uma das limitações desta pesquisa, apesar de ter chegado a resultados semelhantes a outros dois estudos anteriores, continua sendo a impossibilidade de generalização dos resultados para outras organizações.

Recomenda-se que pesquisas futuras estudem o efeito moderador da variável interdependência de tarefas na relação entre os tipos de aprendizagem. Para isso, seria necessário realizar um estudo com diversas empresas representando diferentes segmentos com distintos graus de interdependência de tarefas. Van de Ven, Delbecq e Koenig (I976) e Jehn, Northcraft e Neale (I999) apresentam assertivas validadas que, embora ainda não traduzidas para o português, podem ser úteis para a mensuração desse construto.

Ainda utilizando o conceito de "níveis", uma extensão deste estudo poderia ser feito para incluir, no modelo teórico, o conceito de "fluxos de conhecimento", como foram definidos por Bontis, Crossan e Hulland (2002), para aprofundar o entendimento do processo de aprendizagem.

Finalmente, dado que um dos principais achados foi a relação entre AG e $\mathrm{AO}$, pesquisas qualitativas que revelem os processos formais e informais que favorecem e inibem essa articulação seriam um pré-requisito para propor pesquisas quantitativas mais elucidativas da aprendizagem coletiva nas organizações.

\section{REFERÊNCIAS}

ANTONACOPOULOU, E. P. The relationship between individual and organizational learning: new evidence from managerial learning. Management Learning, v. 37, n. 4, p. 455-473, 2006.

ANTONELLO, C. S. A metamorfose da aprendizagem organizacional: uma revisão crítica. In: RUAS, R. L., ANTONELLO, C. S.; BOFF, L. H. (Org.). Os novos horizontes da gestão: aprendizagem organizacional e competências. Porto Alegre: Bookman. 2005. p. I2-33.

ANTONELLO, C. S.; GODOY, A. S. A produção brasileira em aprendizagem nas organizações: uma metatriangulação. Relatório científico de pesquisa. São Paulo: Fundação de Amparo à Pesquisa do Estado de São Paulo, 2008.

Uma agenda brasileira para os estudos em aprendizagem organizacional. RAE - Revista de Administração de Empresas, v. 49, n. 3, p. 266-28I, jul./set. 2009. 
ARGYRIS, C. D.; SCHÖN, D. Organizational learning II: theory, method, and practice. Reading, MA: AddisonWesley, I996.

BAKER, W. E.; SINKULA, J. M. The synergistic effect of market orientation and learning orientation on organizational performance. Journal of the Academy of Marketing Science, v. 27, n. 4, p. 4II-427, I999.

BAPUJI, H.; CROSSAN, M. From questions to answers: reviewing organizational learning research. Management Learning, v. 35, n. 4, p. 397-4I7, 2004.

BIDO, D. S. et al. Examinando a relação entre aprendizagem individual, grupal e organizacional em uma instituição financeira. In: ENCONTRO DA ASSOCIAÇÃO DOS PROGRAMAS DE PÓS-GRADUAÇÃO E PESQUISA EM ADMINISTRAÇÃO, 32, 2008, Rio de Janeiro. Anais... Rio de Janeiro: Anpad, 2008. I CD-ROM.

BONTIS, N.; CROSSAN, M. M; HULLAND, J. Managing an organizational learning system by aligning stocks and flows. Journal of Management Studies, v. 39, n. 4, p. 437-469, 2002.

BROWN, J.; DUGUID, P. Organizational learning and communities-of-practice: towards a unified view of working, learning and innovation. Organization Science, v. 2, n. I, p. 40-57, I99I.

BUCHNER, A. et al. Software G*Power, versão 3.0.3. Germany: Universidade Kiel, 2006. Disponível em: <http://www.psycho.uni-duesseldorf.de/abteilungen/aap/gpower3/>. Acesso em: i4 nov. 2009.

CHAN, C. C. A. Examining the relationships between individual, team and organizational learning in an Australian Hospital. Learning in Health and Social Care, v. 2, n. 4, p. 223-235, 2003.

CHAN, C. C. A.; LIM, L.; KEASBERRY, S. K. Examining the linkages between team learning behaviors and team performance. The Learning Organization, v. Io, n. 4, p. 228-236, 2003.

CHAN, C. C. A.; PEARSON, C.; ENTREKIN, L. Examining the effects of internal and external team learning on team performance. Team Performance Management, v. 9, n. 7/8, p. I74-I8I, 2003. CHIN, W. W. The Partial Least Squares approach to structural equation modeling. In: MARCOULIDES, G. A. (Ed.). Modern methods for business research. USA: Lawrence Erlbaum Associates, I998. p. 295-336.

CHIN, W. W.; NEWSTED, P. R. Structural equation modeling analysis with small Sample using partial least squares. In: HOYLE, R. H. (Ed.). Statistical strategies for small sample research. Thousand Oaks: Sage Publications, I999. p. 307-34I.

COHEN, J. Statistical power analysis for the behavioral sciences. Revised edition. New York: Academic Press, I977.

COHEN, J. et al. Applied multiple regression/correlation analysis for the behavioral sciences. 3. ed. New Jersey: Lawrence Erlbaum Associaties, 2003.

CROSSAN, M. M.; LANE, H. W.; WHITE, R. E. An organizational learning framework: from intuition to institution. Academy of Management Review, v. 24, n. 3, p. 522-537, I999.

EASTERBY-SMITH, M.; ARAUJO, L. Aprendizagem organizacional: oportunidades e debates atuais. In: EASTERBY-SMITH, M.; BURGOYNE, J.; ARAUJO, L. (Coord.). Aprendizagem organizacional e organização de aprendizagem: desenvolvimento na teoria e na prática. São Paulo: Atlas, 200I. p. I5-38.

EDMONDSON, A. C. Group and organizational influences on team learning. I996. Ph. D. Dissertation-Harvard University, Boston, I996. 
EDMONDSON, A. C. Psychological safety and learning behavior in work teams. Administrative Science Quarterly, v. 44, n. 2, p. 350-383, June I999.

The local and variegated nature of learning in organizations: a group-level perspective. Organization Science, v. I3, n. 2, p. I28-I46, Mar./Apr. 2002.

Learning from mistakes is easier said than done: group and organizational influences on the detection and correction of human error. The Journal of Applied Behavioral Science, v. 40, n. I, p. 66-90, 2004 .

EDMONDSON, A. C.; MOINGEON, B. From organizational learning to the learning organization. Management Learning, v. 29, n. I, p. 5-20, I998.

EDMONDSON, A. C.; MOINGEON, B.; WOOLLEY, A. W. Understanding outcomes of organizational learning interventions. In: EASTERBY SMITH, M.; LYLES, M. (Ed.). The blackwell handbook of organizational learning and knowledge management. Oxford: Blackwell, 2003. p. I85-2II.

FIOL, C. M.; LYLES, M. A. Organizational learning. Academy of Management Review, v. Io, n. 4, p. 803-8I3, I985.

FRIEDMAN, V. J. The individual as agent of organizational learning. In: DIERKES, M. et al. (Ed.). Handbook of organizational learning and knowledge. Oxford: Oxford University Press, $200 \mathrm{I}$. p. 398-4I4.

GHERARDI, S.; NICOLINI, D. The sociological foundations of organizational learning. In: DIERKES, M. et al. (Ed.). Handbook of organizational learning and knowledge. Oxford: Oxford University Press, 200I. p. 35-60.

GOH, S.; RICHARDS, G. Benchmarking the learning capability of organizations. European Management Journal, v. I5, p. 575-583, I997.

HAIR JR., J. F.; ANDERSON, R. E.; TATHAM, R. L.; BLACK, W. C. Análise multivariada de dados. 5. Ed. Porto Alegre: Bookman, 2005.

HOUAISS, A.; VILLAR, M. de S. Minidicionário Houaiss da língua portuguesa. 3. ed. rev. e aum. Rio de Janeiro: Objetiva, 2008.

HUBER, G. Organizational learning: the contributing processes and the literature. Organizational Science, v. 2, n. I, p. 88-II5, I99I.

ISIDRO FILHO, A. Mecanismos de aprendizagem em organizações: desenvolvimento e validação de uma escala de medida. In: ENCONTRO DA ASSOCIAÇÃO NACIONAL DOS PROGRAMAS DE PÓS-GRADUAÇÃO EM ADMINISTRAÇÃO, 3I., 2007, Rio de Janeiro. Anais... Rio de Janeiro: Anpad, 2007. I CD-ROM.

JEHN, K.; NORTHCRAFT, G.; NEALE, M. Why differences make a difference: a field study of diversity, conflict, and performance in workgroups. Administrative Science Quarterly, v. 44, p. 74I763, I999.

KIM, D. H. O elo entre a aprendizagem individual e a aprendizagem organizacional. In: KLEIN, D. A. (Org.). A gestão estratégica do capital intelectual: recursos para a economia baseada em conhecimento. Rio de Janeiro: Qualitymark, I998. p. 6I-92.

LAVE, J.; WENGER, E. Situated learning: legitimate peripheral participation. New York: Cambridge University Press, I99I.

LOIOLA, E.; BASTOS, A. V. B. A produção acadêmica sobre aprendizagem organizacional no Brasil. RAC - Revista de Administração Contemporânea, v. 7, n. 3, p. I8I-20I, jul./set. 2003. 
LÓPEZ, S. P.; PEÓN, J. M. M.; ORDÁS, C. J. V. Organizational learning as a determining factor in business performance. The Learning Organization, v. I2, n. 3, p. 227-245, 2005.

LYLES, M.; EASTERBY-SMITH, M. Organizational learning and knowledge management: agendas for future research. In: EASTERBY SMITH, M.; LYLES, M. (Ed.). The blackwell handbook of organizational learning and knowledge management. Oxford: Blackwell, 2003. p. 639-652.

PAWLOWSKY, P. The treatment of organizational learning in management science. In: DIERKES, M. et al. (Ed.). Handbook of organizational learning and knowledge. Oxford: Oxford University Press, 200I. p. 6I-88.

PETT, M. A.; LACKEY, N. R.; SULLIVAN, J. J. Making sense of factor analysis: the use of factor analysis for instrument development in health care research. California: Sage, 2003.

RINGLE, C. M.; WENDE, S.; WILL, A. SmartPLS 2.0 M3 (beta). Germany: University of Hamburg, 2005. Disponível em: <http://www.smartpls.de>. Acesso em: I4 nov. 2009.

SHRIVASTAVA, P. A typology of organizational learning systems. Journal of Management Studies, v. 20, n. I, p. 7-28, I983.

SLATER, S. F.; NARVER, J. C. Market orientation and the learning organization. Journal of Marketing, v. 59, n. 3, p. 63-74, I995.

SOUZA, R. V.; TREZ, G. Mensuração em aprendizagem organizacional: adaptação de uma escala para o contexto brasileiro. In: ENCONTRO DA ASSOCIAÇÃO NACIONAL DOS PROGRAMAS DE PÓS-GRADUAÇÃO EM ADMINISTRAÇÃO, 30., 2006, Salvador. Anais... Salvador: Anpad, 2006. I CD-ROM.

SUJAN, H.; WEITZ, B. A; KUMAR, N. Learning, orientation, working smart, and effective selling. Journal of Marketing, v. 58, n. 3, p. 39-52, July I994.

TEMPLETON, G. F.; LEWIS, B. R.; SNYDER, C. A. Development of a measure for the organizational learning construct. Journal of Management of Information Systems, v. I9, n. 2, p. I75-2I8, 2002.

TIPPINS, M. J.; SOHI, R. S. It competency and firm performance: is organizational learning a missing link? Strategic Management Journal, v. 24, n. 8, p. 745-76I, 2003.

VAN DE VEN, A. H.; DELBECQ, A.; KOENIG, R. Determinants of coordination modes within organizations. American Sociological Review, v. 4I, p. 322-338, 1976. 